\title{
EVOLUTION OF FUNCTION IN THE MAMMALIAN ORGANISM
}

\author{
By Sir Joseph Barcroft, C.B.E., F.R.S.
}

$\mathrm{T}$ HE life of the mammal is a synthesis of many diverse functions. They range from the digestion of porridge to the performance of Brahms, from snoring to the niceties of mathematical analysis. Here I am concerned neither with the higher faculties of the mind nor with the lower vegetative functions of the body; but merely with that intermediate region of activity which concerns itself with the muscular movements-getting about and the like-these we share with our mammalian relations generally.

A child, for example, learns to walk. It is, so far as locomotion on its legs is concerned, capable of one kind of movement-crude, uncertain toddling. From that movement, however, quite a number of things develop, the initial ability to toddle turns unconsciously into the power either to walk or to run, and these more refined movements, when exploited by conscious intelligence, create the possibility of anything from tap dancing to tight-rope walking.

But instead of interesting ourselves in the variety and complexity of the movements into which toddling may develop, we may look the other way. We may ask : Can it not be that toddling, itself a highly complicated affair, is not a development or differentiation of some much cruder form of movement, and, if so, what is that movement and is it the parent of movements other than toddling, just as toddling is the parent of tap dancing and mastery of the tight rope? By way of parenthesis the words "just as" require a caveat. We ordinarily regard the development of walking from toddling as a question of practice. Can the same be said of intra-uterine movements ?

These are the questions which I wish to attack :

(1) What is the most primitive form of movement of which the mammal is capable?

(2) Does this movement differentiate and develop into other and more complicated ones?

(3) If so, are they recognizable as the forerunners of the sorts of movement with which we are ordinarily familiar in life?

Studies of the earliest movements of which the mammal is capable have been made by a number of observers, mostly on small animals with short

* Substance of a lecture delivered at the Royal Institution on May 20. The lecture was in effect a description of a film illustrating the work of the lecturer in collaboration with Dr. D. H. Barron. Its format was dictated by that fact, especially as regards absence of documentation. Its documentation and its setting in relation to the work of other observers will be found in Dr. Barron's article "The Functional Development of some Mammalian Neuromuscular Mechanism:" (Biol. Rev., 16, 1; 1941). periods of gestation, and from several points of view.

The sheep, for example, has the advantage over small animals in that development in it is a comparatively leisurely affair and its steps are therefore easily recognizable. To quote Barron, "All the events which take place over two months in the sheep are telescoped into a single week by the rat."

The period of gestation in the sheep is twenty-one weeks-147 days; until the thirty-third day of embryonic life, the organism is not capable of any inherent movement apart from the beating of the beart. At this age it is about the length of the thumb nail and it has taken on the general mam. malian form. Its eyes are well developed, its trunk, tail, fore-legs and hind-legs are all there, though in a rudimentary way. The fœtus at this age does not move except in response to a, for it, rather considerable stimulus. This stimulus is quite specific, it must be given in just the right place and the response is perfectly definite. Tap it firmly just under the eye and it will give a twist to its neck. This twist causes the head in the first place to go back, and in the second place to rotate, drawing its nose towards the point of the glass rod, or what not, with which it was tapped. Tapping no other place will elicit a movement.

Why, you may ask, is this particular point on the cheek so different from the rest of the body that a response can be elicited from it and from it alone? There is a very good reason. Here, just beneath the skin, is the end of a nerve. It is the fifth cranial nerve or, rather, a branch of it. It grows down from the brain and will ultimately supply the upper jaw and the nose with sensory fibres. This is the nerve which will impress itself on one's consciousness if one gets a spasm of toothache in the upper jaw or if one smells ammonia. It is perhaps worth noting that regionally it is the nerve which supplies the most anterior part of the body.

In case a sheep were to walk forward (the natural direction of progression) the first bit of it to run into an obstacle would be the tip of its nose, and the nerve.which supplies the tip of the nose is the first sensory nerve to give a response. But by the thirty-third day the fibres of the nerve have not yet reached their destination, they have only reached the point under discussion. The reason why the face must be tapped rather sharply is because the immature endings of the nerve are 
definitely underneath the skin and not in it. The stimulus must be transmitted through the skin to the deeper structure.

The nature of the movement is reflex, that is, it is caused by a peripheral stimulus, which is transmitted to the central nervous system, in this case, the brain, which passes thence to the motor nerve that supplies the neck muscle concerned. That the first movement should be a reflex, or even a movement which involves the nervous system, is not true of all forms of life. Seemingly there is a tendency in the higher forms for neurogenetic movement to appear earlier relatively to myogenic, until, as in the sheep, movements involving the nervous system occur as soon as, or even before, those of a purely muscular character.

So much for the very first movement. In the few days which follow, the principal alteration which occurs is an expansion of that. This expansion takes place in at least four different directions.

(1) The area of skin on the face, the stimulation of which will elicit the movement, becomes greater. Other branches of the fifth cranial nerve, the great sensory nerve of the face, develop, and as they do so the areas of skin which the nerve has reached become sensitive when stimulated and evoke the movement.

(2) The movement itself embraces an everincreasing number of muscles, so that instead of being confined to the neck, it spreads within the next week or so to the mouth, the trunk muscles, the limbs and the tail, so that the movement amounts, not to a twitch of the neck, but to a trifling convulsion of most of the body.

(3) More than this, the response extends not merely in the number of muscles which are involved, but it also extends in respect of time. Stimulation causes not merely one spasm but a series of perhaps twenty spasms, one after the other, amounting to a rhythm.

(4) A much less vigorous stimulus will suffice, as it were, to touch off the trigger of this mechanisma drop of saline on the eye, the direction of a current of fluid into the nose or even a sharp tap on the outside of the sac within which the fœtus floats in its bath of amniotic fluid.

Up to the forty-second day (approximately) the fœtus has exhibited only one kind of movement, the spasm. This may have been more or less widespread, it may have been repeated more or less often, but fundamentally there was but one essential pattern.

Now, however, something quite new is seen. If the fœtus be stimulated, say by a tap on the nose, a rhythm of spasms follows, but the first or first two members of the rhythm differ from the subsequent ones. In the first spasm, the head is thrown back, in the subsequent ones it nods for- wards. This is the commencement of differentiation of movement-for slight as is the difference between the initial and the subsequent spasms, that difference develops into something abundantly evident and of great importance. We have then :

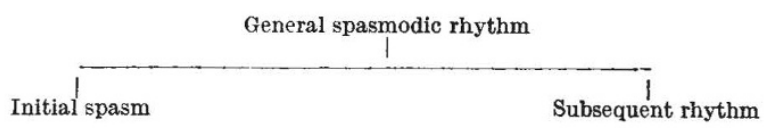

To appreciate what has taken place, we have only to pass on a few days. The trifling difference between the initial and subsequent members of the rhythm is seen to denote a definite splitting of function. The initial spasm is shaping towards an indefinite body movement in which the limbs are largely represented whilst the subsequent rhythm affects principally those muscles which are ultimately concerned with respiration. The initial movement gives one the impression that the fotus is trying to do something; though it is not at all clear what this 'something' may be, the subsequent rhythm gives the impression of the fotus having been mildly out of breath as the result.

Initial spasm
(Somatic in character)

By the forty-eighth or forty-ninth day there is an obvious development of both the somatic and respiratory movements, though in rather different ways. The somatic movement becomes more purposeful in character, the respiratory movement becomes more regulated. Take these movements one by one.

One new element which enters into the somatic movement is gravitational response. When the fœtus is lying on its side, stimulation of the nose causes a twisting of the neck and body, the effect of which is to turn the crown of the head upwards towards the sky. This reaction to gravity is different in some respects from that with which we are familiar in the mature organism. In the latter the semi-circular canals play an active part, but all observers agree that this is not so in the fœtus, or rather in the fœtus at forty-eight days; the response is of a different nature. It is due to the unequal pressure on the two sides of the trunk and perhaps elsewhere. The side on which the fotus is lying naturally bears its weight, and it seems to be the fact that the pressure on this side is the stimulus to the gravitational response. This may not be the whole stimulus, but whether it is or not, if a piece of cardboard be placed firmly on the upper side of the body so that both sides are pressed upon, the gravitational response disappears. 
As regards the limb movements : those of the fore-limbs are not symmetrical either. Both are stretched forwards as far as the knee, but whereas the uppermost fore-leg is stretched right out, all the joints being extended, with the lower fore-limb it is different ; it is flexed at the knee and the toe is pointed backwards.

The whole movement in a crude way seems to be an effort on the part of the fotus to rise from the ground, in just the way which it does shortly after birth. The hind-legs are gathered up underneath the belly of the fœetus. If, then, we may stretch the word progression to include rising from the ground, we may regard the movements seen on the forty. eighth day as containing the germ of progressive movement.

As regards the respiratory type of movement* on the forty-eighth-forty-ninth day, two alterations are taking place.

(1) The first is that the respiratory rhythm becomes daily more easy to evoke. By the fortyninth day almost any muscular movement of the fœetus, however trifling, will touch off a respiratory rhythm; indeed, if at this time the observer lays the foetus in his hand it is scarcely possible to hold it sufficiently still to prevent stray alterations of tension in the muscles from evoking some response.

(2) The second advance in the evolution of function is the gradation of the respiratory rhythm to correspond with the force of the muscular movement which preceded it. Thus, if the fotus be held very still, the respiratory responses due to adventitious movements will be relatively slow and shallow, but if the fœtus be given a sharp tap so that it makes a dramatic effort, that effort is followed by a rhythm which is not only more rapid but is also more powerful. We therefore have reached the following position.

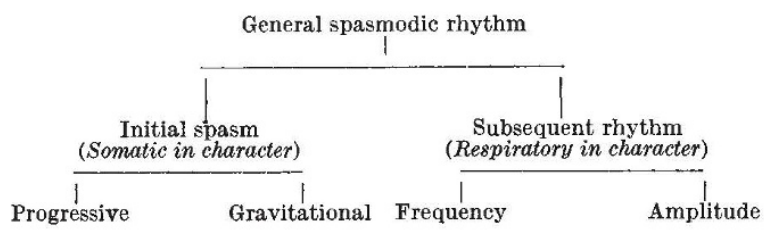

Somewhere about the seventieth day, the movements of the mouth are very prominent. If an object be placed inside the buccal cavity, powerful rhythmic movements are often seen. These resemble both chewing and sucking; it is not quite accurate at this stage to describe them as either, nor is their relation to other movements clear. In this matter, as in many others, we have been helped by the following fact: on exposure or mild asphyxiation of the fotus, its movements

* It must not be supposed that these movements cause anything to go into or out of the chest at this age. The windpipe is not open, and owing to the softness of the chest wall no measurable negative intra-thoracic pressure is induced by the rhythmic movements
the diaphragm, the intercostai muscles and the throat muscles. change ; those functions of the brain which have been developed most recently are first affected, and therefore as the fotus during the progress of this experiment deteriorates in vitality, its movements tend to resemble those which it made at an earlier stage of fotal life. A seventy-day fœetus as it deteriorates will tend in its type of movement shortly to behave like a sixty-day fœtus, then like a fifty-day one, and so on.

In such deteriorating embryos, it may be seen that the rhythmic mouth movements which at seventy days appear to be quite distinct from any others, gradually merge into the general respiratory, from which they have no doubt been differentiated.

I have spoken a great deal about the fifth cranial nerve, and I would end this part of my lecture by collecting some of the points which I have stated about it. The earliest reaction which it gave me was local ; as the fœtus grew, the reaction became widespread, but by the seventieth day it has become strictly localized again. I emphasize this sequence because, though exhibited in its most striking form by the fifth cranial nerve, it is true of all sensory nerves, the reaction to stimulation of them being, initially, local, becoming more widespread but finally settling to a local response.

The following chart sums up, so far as we can go here, the information at our disposal about the differentiation of actions of various sorts :

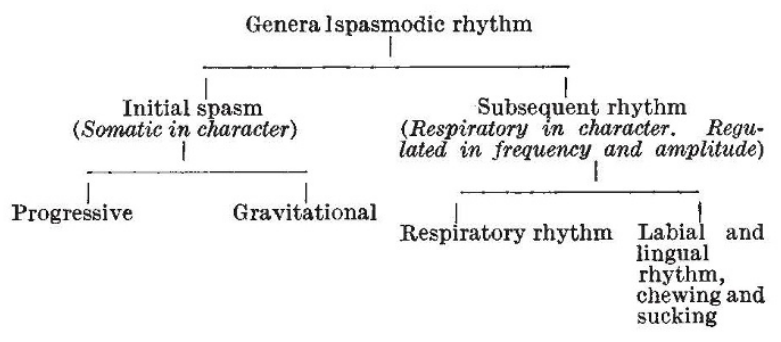

\section{Character of Movement}

Hitherto I have spoken of the evolution of a number of actions, if I may describe them by that term, breathing, chewing, getting up and the like. But any of these actions may change in character ; it may be rapid, jerky and spasmodic, or it may be drawn out and gradual, or, again, it may even be a sustained movement in which there is an actual static phase, such as the Nazi salute. The evolution of the actions which I have described has all concerned itself with those parts of the central nervous system into which sensory nerves enter and from which motor nerves leave-the hindermost part of the brain (the medulla) and the spinal cord. In general, the organization of action takes place from above downwards, and it is initiated at the point of entry of the nerve which receives sensations from the face and nose and is modified later by influences entering the spinal 
cord from the arms, the trunk and the legs. But if in the central nervous system this evolution of function takes place from the point of entry of the facial nerve backwards, it takes place in a different sense from that same point progressively forwards. The forward development is concerned less with what the fotus does, than with how he does it.

The first movement of all was a simple twitch or a minute spasm; when later it became necessary to expand this twitch into something which stretched over a longer time, the expansion consisted of the extension of a single twitch into a series of twitches-a rhythm, but the character of each individual jerk of which the rhythm consisted was unaltered; even when differentiation commenced the twitches were still twitches.

Between the forty-fifth and fiftieth days, however, the movements gradually assume a different character, namely, they take on an air of deliberation ; if the arm is thrust out, the movement is less that of the boxer getting in his punch than that of the constable raising his hand to stop the traffic.

Just as the jerky movements obtained from the lower parts of the central nervous system gradually took on a certain appearance of purposefulness and became evidently the forerunners of the types of movement which we actually recognize, so these sustained movements also tend to fall into certain patterns which we recognize as postural. In assoc. iation with the turning of the neck to which I have already alluded, there are harnessed the corresponding movements of the legs, that is, the foreleg on the side to which the nose is turned is extended, whilst the other fore-leg tends to be flexed or partially so. At a later date, characteristic postural movements of the hind-legs, the trunk and the eyes are associated with this twisting of the neck. Indeed, it is only necessary to take the head between one's fingers and rotate the neck alternately in one direction and then in the other to produce this corresponding marionette-like movement of the eyes and limbs.

These postural movements are essentially those described by Magnus and de Klejn; the difference between their demonstration of the movements on the adult animal and our own on the fotus is that they, in order to secure the movements, had to perform a surgical operation in which the midbrain was relieved of the influence which dominated it, notably the semi-circular canals. In the case of the fifty-five day sheep's fœetus, no such surgical operation is necessary because what Magnus and de Klejn cut away has not at this age functionally developed. The alteration from the simple jerky type of movement to the more deliberate postural type is attributable to this development of the mid-brain and its influence on the centres below it.

The initial phase of postural movement soon disappears; by the sixtieth day, if the fœtus be delivered, it exhibits a different picture, the forelegs are tensely stretched out side by side, the head and the tail are extended, and the foetus presents the appearance of an animal suffering from what is known as 'decerebrate rigidity'-a condition which, again, can only be obtained in the adult by a surgical operation, that of severing the foremost parts of the brain from parts behind them, and so ridding these latter from the influence of the higher centres. But once more, in the case of the sixtyday fœtus, no surgical operation is necessary for the simple reason that the higher centres in question have not developed physiologically-function has developed upwards far enough, but only far enough to produce this rigidity.

The picture of rigidity does not last many days. From about the fiftieth day onwards a characteristic has been gradually creeping into the picture, slight at first, but quite evident; by the seventieth day it becomes dominant, namely 'inhibition'. During the eighth and ninth weeks, this growing inhibition amounts to no more than a certain evident restriction of movement associated with the postural patterns which I have described. On the seventieth day, however, if the fœetus be delivered, so far from exhibiting spasmodical or postural movements, it gives the impression of being dead or at all events soundly asleep. If mechanically stimulated, the stimulus must be strong if it is to be effective, and even at that the response is only very restricted. This suppression of movement means that function has progressed well up into the fore brain. That motility has not been abolished but only suppressed is easily proved. It is only necessary to leave the fœtus exposed for a while or to pinch the umbilical cord in order to uncover the functions which I have tried to describe. A more elegant proof is furnished by intra-uterine transection of the central nervous system. It is possible to cut across the brain or cord at any given point, between the fiftieth and seventieth days, without impairing the growth of the fotus. If, at seventy days, the section consists in mere severance of the cerebral hemispheres from the rest of the central nervous system, no change in the behaviour of the fotus can be seen, but if the section is lower down -about the middle of the fore brain-the lower parts are freed from 'inhibition' and the foetus exhibits the 'rigidity' pattern of sixty days. If the section is just below the 'pons Varolii', the fotus exhibits almost unceasing jerky movements, which are both somatic and respiratory and are strongly reminiscent of a fœetus of about forty-fifty days. At seventy days, however, the fœetus appears to be in a sound sleep and in this sleep we may leave it. 